\title{
Establishment of prediction models of trapped sediment mass and total filtration efficiency of pre-pump micro-pressure filter
}

\author{
Qiao $\mathrm{Li}^{1,2} \cdot$ Zijing Wu$^{1,2} \cdot$ Hongfei Tao ${ }^{1,2} \cdot$ Mahemujiang Aihemaiti ${ }^{1,2} \cdot$ Youwei Jiang ${ }^{1,2} \cdot$ Wenxin Yang $^{1,2}$
}

Received: 16 July 2021 / Accepted: 21 January 2022 / Published online: 13 February 2022

(c) The Author(s) 2022

\begin{abstract}
The filter before a pump is a key piece of equipment of a micro-irrigation system, which can ensure safe and stable operation. This paper examines a pre-pump micro-pressure filter, using the trapped sediment mass and total filtration efficiency as the assessment indicators. Orthogonal experiments of the physical model of the inlet flow, sediment content, water separator type, and filter area were conducted. The experimental results were processed by analysis of variance, dimensional analysis, and multiple regression analysis. The influences of the factors affecting the trapped sediment mass in descending order were the sediment content, filter area, water separator type, and inlet flow. The influences of the factors affecting the total filtration efficiency in descending order were the filter area, sediment content, water separator type, and inlet flow. While the water separator type significantly affected the trapped sediment mass and total filtration efficiency, the difference between the different treatments was insignificant. The prediction model for the trapped sediment mass (total filtration efficiency) was established with an $R^{2}$ of $0.998(0.889)$. Since the relative errors between the predicted and measured values were less than $6 \%$, these models could produce accurate predictions. These results provide technical support for the structural optimization and filtration mechanism of the filter and advance the theory of micro-pressure filtration.
\end{abstract}

\section{Introduction}

For a micro-irrigation system that relies on surface water as the irrigation water source, to prevent the irrigator from clogging, a sedimentation tank is usually set up to collect the sediment. A separate or combined filter is then installed for further filtering, so that the filtered water can be transported to a pipeline system for micro-irrigation. At present, the commonly used filters for filtration include sand, mesh, and disc filters (Adin 1987; Capra and Scicolone 2007; Liu et al. 2021; Demir et al. 2009).

Researchers have mainly adopted physical experiments combined with dimensional analysis, numerical simulations, and other methods to study the hydraulic and filtration performances of filters. Mesquita et al. (2012) studied the influence of the media bed characteristics and the internal auxiliary components on the head loss

Hongfei Tao

304276290@qq.com

1 College of Hydraulic and Civil Engineering, Xinjiang Agricultural University, Urumqi 830052, China

2 Xinjiang Key Laboratory of Hydraulic Engineering Security and Water Disasters Prevention, Urumqi 830052, China of the sediment filter. Based on dimensional analysis, Elbana et al. (2013) developed a mathematical model to calculate the head loss of a micro-irrigation sand filter, which had high precision and accuracy. In the study of the pressure drop of different filtration media, Bové et al. (2015) measured the pressure drops for surface velocities of $0.004-0.025 \mathrm{~m} / \mathrm{s}$ and established a new formula to quantify the pressure drops of quartz sand, glass beads, and surface-modified glass. Garcia et al. (2018) selected the gradient boosting regression tree method as the starting point, combined it with a differential evolution technique, and formulated a sand filter pressure drop model for micro-irrigation. García-Gonzalo et al. (2020) established a model that could predict the dissolved oxygen value at the outlet of a sand filter by a Gaussian process regression (GPR) based on parameters such as the height of the filter bed, filtration velocity, and filter inlet values of the electrical conductivity, dissolved oxygen, $\mathrm{pH}$, turbidity, and water temperature. Elbana et al. (2012) used a reclaimed effluent to evaluate the efficiencies of sand filters with sand effective diameters of $0.32,0.47,0.63$, and $0.64 \mathrm{~mm}$ at decreasing the turbidity and improving the dissolved oxygen concentration. De Deus et al. (2020) evaluated the influence of the structural design, particle size, and 
filter height on the pressure loss and surface velocity of an expanded filter layer during the backwashing process of three types of sand filters. Based on dimensional analysis, Puig-Bargues et al. (2005) established a general mathematical model for calculating the head loss of a mesh filter for micro-irrigation. They reported the consistency of the modelled head loss with the experimental data. Based on the research results of Puig-Bargues et al. (2005) and Yurdem et al. (2008), Duran-Ros et al. (2010) also utilized dimensional analysis to derive and formulate a new mathematical model of head loss that was more realistic after testing. Wu et al. (2014) combined experimental data and dimensional analysis to establish an improved mathematical model for calculating the head loss. On the basis of the above research results, Zong et al. (2015) first combined the experimental data with 11 factors that affected the head loss and then applied dimensional analysis to establish the head loss equations of a self-cleaning mesh filter under clean and turbid water conditions, which enabled more accurate predictions of the head loss. Elbana et al. (2012) studied the performance of a sand filter, discussed the effect of the effective particle size of the sand on the effluent quality, and determined that its maturity period was 15 min. Li et al. (2016a, 2018) used an Eulerian model to simulate the backwashing process of three types of quartz sand filtration layers with equivalent particle sizes of 1.06, 1.2 , and $1.5 \mathrm{~mm}$. The Gambit software was used for modelling and mesh generation, and the "Mixture" model was adopted as the backwashing simulation model. By studying the factors affecting the filtration effects of sand filters, Zhang et al. (2020) suggested that the thickness of the filter layer and the sediment content of the raw water could significantly affect the turbidity and particle mass concentration, while the filtration rate and sediment content of the raw water could considerably influence the head loss. Jiao et al. (2020) analysed the effects of different particle sizes of the filter media, filtration flow rate, and backwash flow rate in the sand filter on the filtration performance of the Yellow River water. That study revealed that the optimal operating conditions consisted of filter media with particle diameters of $1.7-2.35 \mathrm{~mm}$, a filtration flow rate of $0.018 \mathrm{~m} / \mathrm{s}$, and a backwash flow rate of $0.022 \mathrm{~m} / \mathrm{s}$. De Souza et al. (2021) set up two sand filters to operate under the same conditions, compared the effects of backwashing and scraping methods on the biomass, and proposed a new biomass method to evaluate the filtration efficiency. SoléTorres et al. (2019a, b) discussed the effects of three drainage design types, two filter material heights, and two filtration rates on the filtration performance of micro-irrigation sand filters. Additionally, the recycled water filtered by three sand filters with different drainage designs was pressurized and transported to pressure-compensating emitters with a flow rate of $2.3 \mathrm{~L} / \mathrm{h}$. The results showed that these three sand filters had insignificant effects on the proportion of complete clogging of the emitter.

Pujol et al. (2020a, b) conducted numerical simulations on three types of sand filter drainage designs, and the results showed that the uniformity of the filter flow was the key to achieving low pressure drops. The filter pressure drop mainly comes from the pressure loss of sand, and the optimal drainage type is the spike type. Mesquita et al. (2019) used a numerical simulation to evaluate the hydraulic performance of the diffuser in a sand filter. The results showed that the diffuser improved the uniformity of the flow on the sand bed surface and reduced the bed surface deformation. Zong et al. (2019) pointed out that the flushing pressure values of the filter screen with apertures of 0.178 and $0.124 \mathrm{~mm}$ were 60.0 and $70.0 \mathrm{kPa}$, respectively, and the best flushing time was 30-45 s. Zhou et al. (2020) implemented a CFD-DEM (computational fluid dynamics-discrete element method) coupled numerical simulation method to study the flow patterns and the movement of water and sediment in a Y-type mesh filter with/without guide vanes. Their study indicated that the installation of guide vanes improved the anti-clogging performance of the filter. Yang et al. (2019a, b) constructed a comprehensive method for evaluating the filtration performance of disc filters. Furthermore, they improved the size of the disc filter, and optimized its filtering performance. In addition, through fractal theory, a new filter stack channel design was proposed to reduce the local head loss and improve the sediment interception in terms of the volume and particle size.

Sand, mesh, and disc filters play an important role in the first hub of a micro-irrigation system. However, they all operate by post-pump forced pressure filtration and flushing, i.e., after the water enters the pump, it completes the filtration or flushing under high-pressure conditions.

To address the issues of a large head loss, high energy consumption, huge initial investment, and unstable filtration effects of the filters used for agricultural micro-irrigation at present, and to meet the requirements of low carbon emissions and environmental protection ( $\mathrm{Li}$ et al. 2016b), a prepump micro-pressure filter was designed. It was named this because the filter was installed before the pressurized water pump, and the natural water head at the tail of the sedimentation tank was used for filtering and flushing. A patent for this system has been applied (Tao et al. 2020a). The filtering performance of the filter is crucial for determining the dirt transportation and deposition in the filter. The existing research results were all acquired under high-pressure conditions. If the boundary conditions change (i.e., from high-pressure conditions to micro-pressure conditions), the filtration characteristics will change. Therefore, it is necessary to study the pre-pump micro-pressure filter. In this study, indoor physical model experiments of the influence of the sediment content, flow rate, water separator type, and 
filter area were conducted to examine the filtration performance of the pre-pump micro-pressure filter. Statistical and dimensional analyses were utilized to analyse the test results (Tao et al. 2020b). The orders of the factors affecting the trapped sediment mass and total filtration efficiency of the pre-pump micro-pressure filter were obtained, and prediction models for the trapped sediment mass and total filtration efficiency were constructed. These research results can provide a basis for predicting the filtration performance of a pre-pump micro-pressure filter, which is of practical significance. Furthermore, the results obtained can improve the solid-liquid separation and filtration theory.

\section{Materials and methods}

\section{Experimental setup and working principle}

The circulation system of the pre-pump micro-pressure filter was composed of a mixing tank, a reservoir, a pre-pump micro-pressure filter, and connecting pipes. The pre-pump micro-pressure filter consisted of a filter tank, water separator, and stainless-steel filter screen (as shown in Fig. 1). Both the reservoir and filter tank were made of a transparent acrylic board with a thickness of $7 \mathrm{~mm}$, which allowed the experimental phenomena to be observed easily. The internal dimensions of the reservoir were a length of $500 \mathrm{~mm}$, width of $300 \mathrm{~mm}$, and height of $600 \mathrm{~mm}$. The filter tank had a width of $300 \mathrm{~mm}$ and a height of $430 \mathrm{~mm}$, and its length could be adjusted to 505, 705, and $915 \mathrm{~mm}$ with corresponding filter areas of 1105,1582 , and $2060 \mathrm{~cm}^{2}$, respectively. As shown in Fig. 2, the type-1, type-2, and type-3 water separators differed in terms of the shape of the head and tail. The water separator was composed of three parts: a head, a middle section, and a tail. The lengths of the head and tail were $60 \mathrm{~mm}$, and the length of the middle section was $300 \mathrm{~mm}$. The head of the type-1 water separator was rotated by the fitting curve, and the head of type- 2 water separator was rotated by the elliptic curve with a long axis of $120 \mathrm{~mm}$ and a short axis of $40 \mathrm{~mm}$. The head of the type- 3 water separator was a round platform, in which the radius of the upper base was $5 \mathrm{~mm}$ and the radius of the lower base was $20 \mathrm{~mm}$. The diameters of the inlet pipe and backwater pipe were $50 \mathrm{~mm}$, and the diameters of the connecting pipe and outlet pipe were $75 \mathrm{~mm}$. The experimental flow was controlled by adjusting the openings of the inlet valve and backwater valve, and the flow was measured by a handheld ultrasonic flowmeter.

The working principle of the pre-pump micro-pressure filter used in practice is that the sediment particles in the surface water first settle through the sedimentation tank and then flow into the filter from the outlet pipe at the tail of the sedimentation tank. The water flow is filtered from the inside out, and the clean water flows out from the mesh after filtering. With the progress of filtration, impurities gradually accumulate in the filter screen. When the filter screen is blocked to a certain extent, sewage treatment must be carried out to restore the filtering capacity and filtration efficiency

Fig. 1 Schematic diagram of the micro-pressure filter circulation system before the pump. 1. Reservoir; 2 . inlet valve; 3. water separator; 4. inlet; 5 . filter tank; 6 . outlet; 7 . filter screen; 8 . outlet valve; 9. sewage collection filter screen; 10 . sewage valve; 11. stirring pump; 12. mixing tank; 13. mud pump; 14. backwater valve; 15 . inlet valve

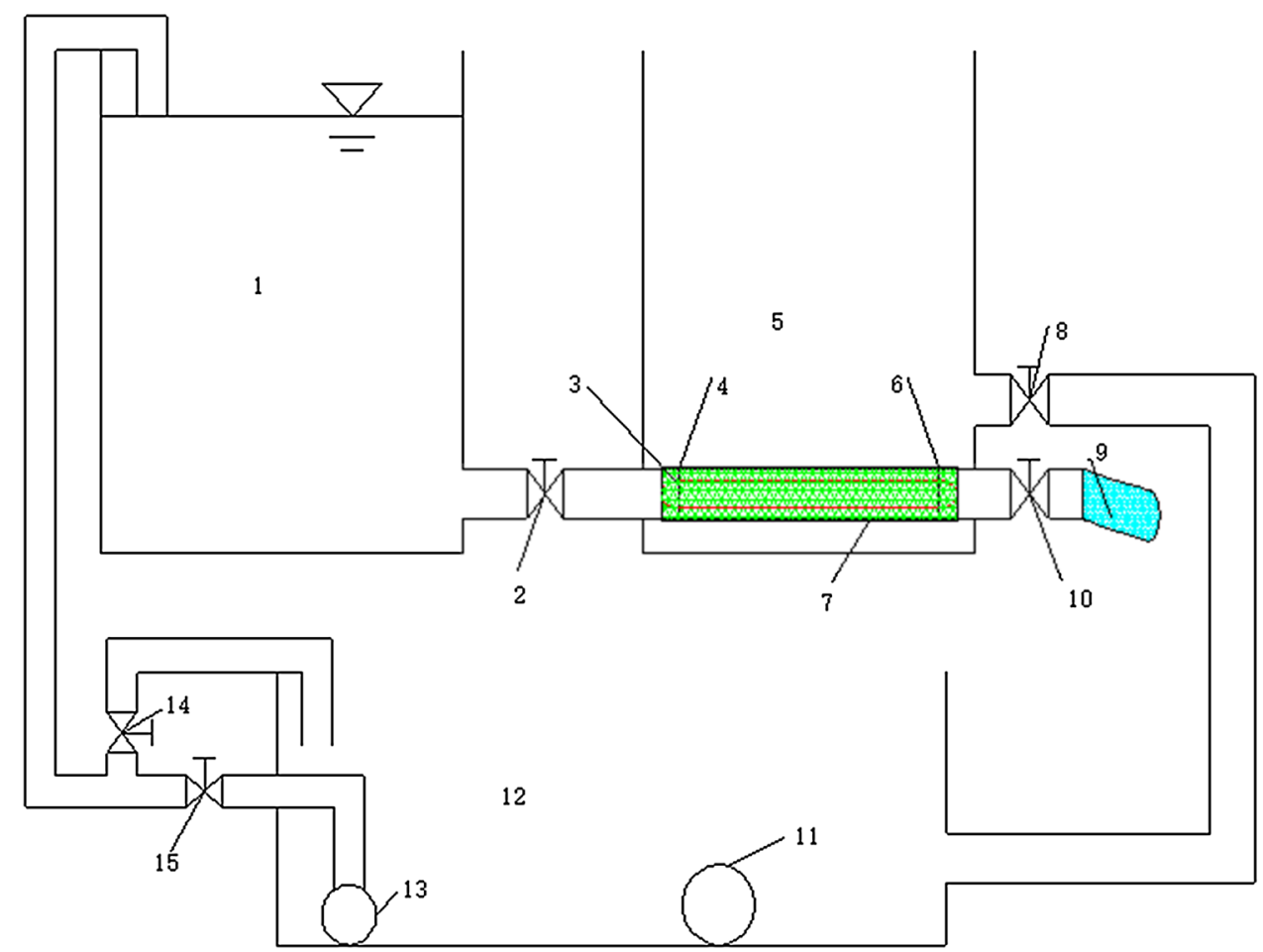


fig. 2 Three-dimensional diagram of water separators

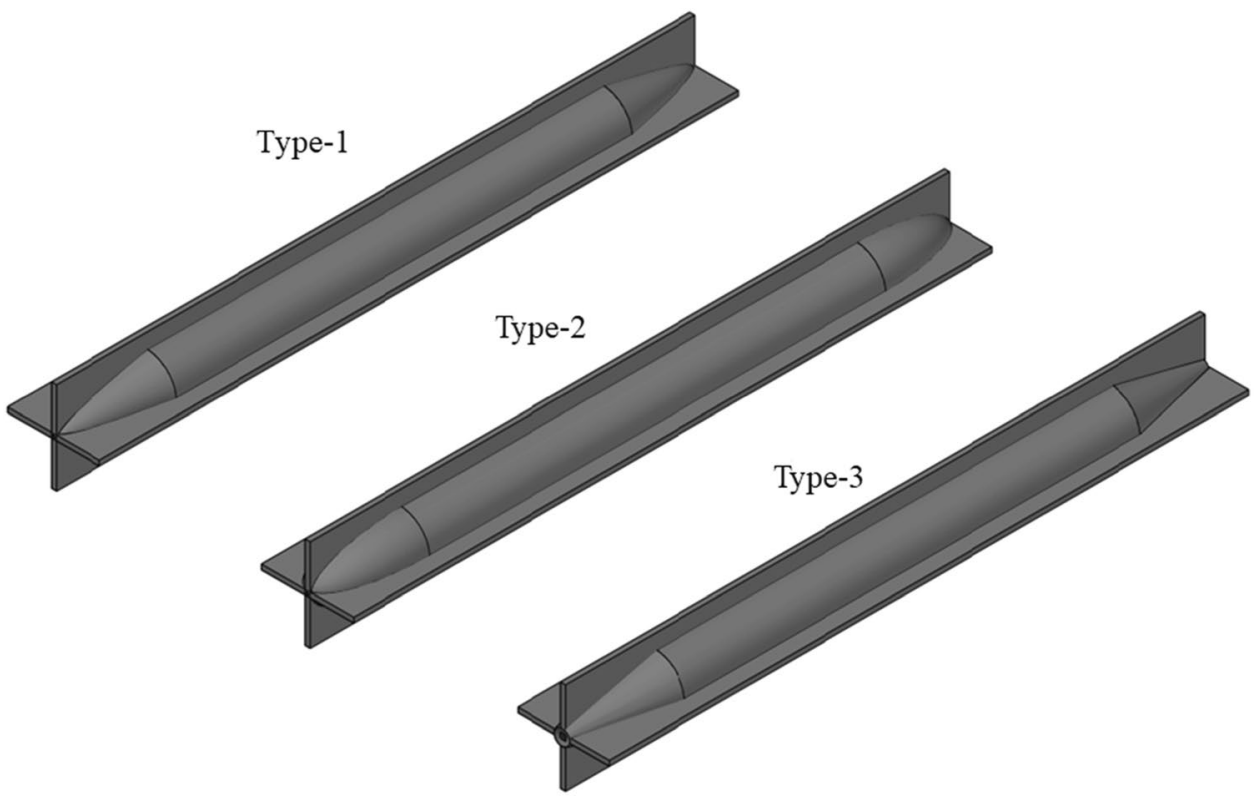

of the filter. At this time, the discharge valve is opened to realize hydraulic sediment discharge under the action of the natural head of the sedimentation tank. It is also possible to perform manual flushing and remove the water separator, so that the filter screen can be washed manually. After flushing, the water separator can be reinstalled.

\section{Experimental setup and materials}

The pre-pump micro-pressure filter uses a combination of a filter tank and a stainless-steel filter screen to filter the sandy water flow to achieve agricultural micro-irrigation. The experimental water supply device was a cylinder with a diameter of $0.8 \mathrm{~m}$, a length of $1.5 \mathrm{~m}$, and a height of $0.33 \mathrm{~m}$. The sediment samples used in the test were configured based on the particle size of the sediment at the end of the sedimentation tank in the drip irrigation system. However, to shorten the test time and observe the experimental phenomenon, the sediment samples with $2.13 \%$ (particle size $0.25-0.5 \mathrm{~mm}$ ) and $0.04 \%$ (particle size $0.5-1 \mathrm{~mm}$ ) were added. As the particle sizes were relatively small, they could be considered to be similar to a real scenario. To ensure the stability of the sediment content during the experiment and prevent the sediment particles from depositing at the bottom of the cylinder and interfering with the experimental phenomena, a funnel was used to add sediment evenly, and a water pump was used to mix the sediment particles uniformly. The test equipment mainly included a stirring pump, mud pump, and handheld ultrasonic flowmeter (Table 1). The particle size distribution of the test sediment samples is shown in Table 2.

\section{Orthogonal experiment design}

For the turbid water experiment, the investigated factors were the inlet flow, sediment content, filter area, and water separator type. The test indicators were the trapped sediment

Table 1 Experimental setup

\begin{tabular}{llll}
\hline Name & Model/specification & Number & Usage \\
\hline Stirring pump & W6-12.5-0.75 & 1 & To stir the tap water and silt evenly \\
Mud pump & WQD12-20-1.5 & 1 & To input the test water source into the system \\
Handheld ultrasonic flowmeter & MSDS-3000H & 1 & To measure the flow rate during the experiment \\
Electronic balance & YP2002N & 1 & To weigh the mass of the sample \\
Electric heating thermostat & DHG series & 1 & To dry the wet sediment samples and filter paper \\
Infrared thermometer & DE6830B & 1 & To measure the water temperature during the experiment \\
Stopwatch & - & 1 & To record the time \\
Digital camera & Canon EOS 77D & 1 & To photograph the experimental phenomena \\
Plastic measuring cylinder & $1000 \mathrm{ml}$ & 25 & To collect samples \\
Filter paper & $\varnothing 18 \mathrm{~cm}$ qualitative filter paper & 3 & To filter the sediment in the water sample \\
\hline
\end{tabular}


Table 2 Particle size distribution of test sediment samples

\begin{tabular}{llllll}
\hline Name & \multicolumn{5}{l}{ Particle content $(\%)$} \\
\cline { 2 - 6 } & $<0.075 \mathrm{~mm}$ & $0.075-$ & $0.1-$ & $0.25-$ & $0.5-1 \mathrm{~mm}$ \\
& & $0.1 \mathrm{~mm}$ & $0.25 \mathrm{~mm}$ & $0.5 \mathrm{~mm}$ & \\
\hline $\begin{array}{c}\text { Sediment } \\
\text { sample }\end{array}$ & 2.83 & 1.07 & 93.93 & 2.13 & 0.04 \\
\hline
\end{tabular}

Table 3 Orthogonal experiment design

\begin{tabular}{|c|c|c|c|c|}
\hline Test & Inlet flow & Sediment content & $\begin{array}{l}\text { Water separator } \\
\text { type }\end{array}$ & Filter area \\
\hline 1 & $4\left(7 \mathrm{~m}^{3} / \mathrm{h}\right)$ & $2(1.0 \mathrm{~g} / \mathrm{L})$ & 3 (type-2) & 2 \\
\hline 2 & $1\left(2 \mathrm{~m}^{3} / \mathrm{h}\right)$ & $1(0.5 \mathrm{~g} / \mathrm{L})$ & 1 (no separator) & $1\left(1105 \mathrm{~cm}^{2}\right)$ \\
\hline 3 & 4 & 1 & 1 & $2\left(1582 \mathrm{~cm}^{2}\right)$ \\
\hline 4 & $2\left(4 \mathrm{~m}^{3} / \mathrm{h}\right)$ & 1 & 4 (Type-3) & 1 \\
\hline 5 & 5 & $4(2.0 \mathrm{~g} / \mathrm{L})$ & 2 (Type-1) & 1 \\
\hline 6 & 2 & $5(2.5 \mathrm{~g} / \mathrm{L})$ & 1 & 2 \\
\hline 7 & $5\left(8 \mathrm{~m}^{3} / \mathrm{h}\right)$ & $3(1.5 \mathrm{~g} / \mathrm{L})$ & 4 & 2 \\
\hline 8 & 4 & 4 & 4 & 1 \\
\hline 9 & $3\left(6 \mathrm{~m}^{3} / \mathrm{h}\right)$ & 4 & 1 & $3\left(2060 \mathrm{~cm}^{2}\right)$ \\
\hline 10 & 5 & 2 & 1 & 2 \\
\hline 11 & 2 & 4 & 3 & 2 \\
\hline 12 & 4 & 3 & 1 & 1 \\
\hline 13 & 3 & 2 & 1 & 1 \\
\hline 14 & 2 & 3 & 1 & 3 \\
\hline 15 & 5 & 5 & 1 & 1 \\
\hline 16 & 1 & 5 & 3 & 1 \\
\hline 17 & 3 & 5 & 4 & 2 \\
\hline 18 & 1 & 2 & 4 & 3 \\
\hline 19 & 4 & 5 & 2 & 3 \\
\hline 20 & 3 & 1 & 2 & 2 \\
\hline 21 & 1 & 3 & 2 & 2 \\
\hline 22 & 3 & 3 & 3 & 1 \\
\hline 23 & 5 & 1 & 3 & 3 \\
\hline 24 & 1 & 4 & 1 & 2 \\
\hline 25 & 2 & 2 & 2 & 1 \\
\hline
\end{tabular}

mass and total filtration efficiency. The selected factors and levels were as follows: inlet flow $Q: 2,4,6,7$, and 8; sediment content $S: 0.5,1.0,1.5,2.0$, and $2.5 \mathrm{~g} / \mathrm{L}$; water separator type $C$ : no separator, type-1, type-2, and type-3; filter area $A: 1105,1582$, and $2060 \mathrm{~cm}^{2}$. The blank column was used as a control. The turbid water orthogonal experimental design with a total of 25 groups of experiments is shown in Table 3.

\section{Experimental procedure}

By closing the sewage valve, adjusting the opening of the inlet valve to the design flow rate, adding the weighed sediment, and turning on the agitator pump to mix the water and sediment evenly, the turbid water was sucked into the filter system by the mud pump to start the filtering process. During the experiment, the water level in the reservoir and filter tank under different test conditions and different filtration times were recorded. The inlet flow rate under the corresponding time conditions was recorded. Turbid water samples at the end of the outlet pipe were collected and dried to obtain the sediment content of the effluent. After the experiment, the sediment particles that accumulated in the filter screen and the sediment that deposited at the bottom of the filter tank were weighed. After completing each group of turbid water experiments, the entire test device was cleaned. All the tests were performed by following an orthogonal experimental design.

\section{Experimental indicators}

The total filtration efficiency $(\eta)$ is the average value of the filtration efficiency in the filtration process. The filtration efficiency is defined as follows:

$\eta=\frac{S_{1}-S_{2}}{S_{1}} \times 100 \%$,

where $S_{1}$ is the sediment content of the water flow before filtration, and $S_{2}$ is the sediment content of the flow after filtration (outlet). The filtration efficiency reflects the percentage of the filter's interception of impurities in the water. A higher filtration efficiency will lead to better water quality after filtration, and the system will be better at meeting the irrigation requirements.

The trapped sediment mass is denoted as $R_{m}$. When the filter operates under different experimental conditions, the mass of the sediment trapped in the filter will differ due to the differences in the inlet flow, sediment content, filter area, and water separator type. The influence of different experimental conditions on the mass of intercepted sediment was analysed, the key parameters affecting the quality of intercepted sediment were determined, and the sediment interception capacity of the device was improved.

\section{Research methods}

The analysis of variance (ANOVA) was used to process the test results. The significance level of a factor on the assessment index was judged based on the $P$ value. In the ANOVA, $P>0.05$ indicates that there is no significant difference; $\mathrm{P}<0.05$ indicates a significant difference, marked with $* P<0.01$ indicates an extremely significant difference, marked with $* * P<0.001$ is marked with $* * *$ (Dai et al. 2016). 
In this paper, the parameters in the regression equation were estimated by the least squares method to find the relationship between the test indices and the multiple factors. First, dimensional analysis was applied to determine the factors affecting the trapped sediment mass and the total filtration efficiency, and the values of the relevant dimensionless terms were calculated (Price 2003). Then the SPSS 25.0 software was used to conduct multiple regression analysis on 20 groups of data to obtain the relevant parameters. Finally, the prediction model of the trapped sediment mass and the total filtration efficiency of the pre-pump micro-pressure filter was constructed. Then the model is verified using the reserved five groups of test data.

\section{Results and discussion}

\section{Orthogonal experiment results}

The orthogonal experiments of the indoor physical model were conducted, and the results of the trapped sediment mass and total filtration efficiency are presented in Table 4.

\section{Analysis of orthogonal experiment results}

\section{Analysis of variance of trapped sediment mass}

The analysis of variance results for the trapped sediment mass is shown in Table 5. The sediment content had the most significant impact on the trapped sediment mass under turbid water conditions (Table 5). This indicated that the sediment content was the most critical factor affecting the filter's trapped sediment mass, followed by the filter area, then the water separator type, and finally, the inlet flow (insignificant effect).

Table 4 Orthogonal experiment results

\begin{tabular}{|c|c|c|c|c|c|c|c|}
\hline Test number & $\begin{array}{l}\text { Inlet flow } \\
\left(\mathrm{m}^{3} / \mathrm{h}\right)\end{array}$ & $\begin{array}{l}\text { Sediment con- } \\
\text { tent }(\mathrm{g} / \mathrm{L})\end{array}$ & Water separator type & Filter area $\left(\mathrm{cm}^{2}\right)$ & $\begin{array}{l}\text { Blank } \\
\text { column }\end{array}$ & $\begin{array}{l}\text { Trapped sedi- } \\
\text { ment mass (g) }\end{array}$ & $\begin{array}{l}\text { Total } \\
\text { filtration } \\
\text { efficiency }\end{array}$ \\
\hline 1 & 7 & 1 & Type-2 & 1582 & 3 & 212.6 & 0.908 \\
\hline 2 & 2 & 0.5 & No separator & 1105 & 1 & 103 & 0.895 \\
\hline 3 & 7 & 0.5 & No separator & 1582 & 2 & 105.6 & 0.920 \\
\hline 4 & 4 & 0.5 & Type-3 & 1105 & 3 & 106.8 & 0.916 \\
\hline 5 & 8 & 2 & Type-1 & 1105 & 2 & 400.1 & 0.844 \\
\hline 6 & 4 & 2.5 & No separator & 1582 & 2 & 497.4 & 0.859 \\
\hline 7 & 8 & 1.5 & Type-3 & 1582 & 1 & 323.3 & 0.895 \\
\hline 8 & 7 & 2 & Type-3 & 1105 & 5 & 420.85 & 0.860 \\
\hline 9 & 6 & 2 & No separator & 2060 & 3 & 409.6 & 0.885 \\
\hline 10 & 8 & 1 & No separator & 1582 & 5 & 201.1 & 0.893 \\
\hline 11 & 4 & 2 & Type-2 & 1582 & 1 & 426.3 & 0.882 \\
\hline 12 & 7 & 1.5 & No separator & 1105 & 4 & 293.4 & 0.847 \\
\hline 13 & 6 & 1 & No separator & 1105 & 1 & 199.2 & 0.863 \\
\hline 14 & 4 & 1.5 & No separator & 2060 & 5 & 309.6 & 0.891 \\
\hline 15 & 8 & 2.5 & No separator & 1105 & 3 & 475.9 & 0.830 \\
\hline 16 & 2 & 2.5 & Type-2 & 1105 & 5 & 500.1 & 0.844 \\
\hline 17 & 6 & 2.5 & Type-3 & 1582 & 4 & 523 & 0.891 \\
\hline 18 & 2 & 1 & Type-3 & 2060 & 2 & 215.2 & 0.930 \\
\hline 19 & 7 & 2.5 & Type-1 & 2060 & 1 & 521.4 & 0.885 \\
\hline 20 & 6 & 0.5 & Type-1 & 1582 & 5 & 106.9 & 0.941 \\
\hline 21 & 2 & 1.5 & Type- 1 & 1582 & 3 & 317.5 & 0.902 \\
\hline 22 & 6 & 1.5 & Type-2 & 1105 & 2 & 301.5 & 0.855 \\
\hline 23 & 8 & 0.5 & Type-2 & 2060 & 4 & 107.2 & 0.956 \\
\hline 24 & 2 & 2 & No separator & 1582 & 4 & 404.7 & 0.866 \\
\hline 25 & 4 & 1 & Type-1 & 1105 & 4 & 205.3 & 0.895 \\
\hline
\end{tabular}


Table 5 Analysis of variance of the trapped sediment mass

\begin{tabular}{lrrrrr}
\hline Source of error & Sum of squares & $\begin{array}{l}\text { Degree of } \\
\text { freedom }\end{array}$ & Mean square & $F$ value & $P$ value \\
\hline Inlet flow & 248.006 & 4 & 62.002 & 1.182 & $3.714 \mathrm{E}-01$ \\
Sediment content & $501,171.628$ & 4 & $125,292.907$ & 2388.086 & $4.434 \mathrm{E}-16^{* * *}$ \\
Water separator type & 1161.915 & 3 & 387.305 & 7.382 & $5.547 \mathrm{E}-03^{* *}$ \\
Filter area & 792.438 & 2 & 396.219 & 7.552 & $8.625 \mathrm{E}-03^{* *}$ \\
Error & 577.124 & 11 & 52.466 & & \\
Total & $503,951.112$ & 24 & & & \\
\hline
\end{tabular}

$* * * P<0.001, * * P<0.01, * P<0.05$
Table 6 Analysis of variance of the total filtration efficiency

\begin{tabular}{llllrl}
\hline Source of error & Sum of squares & $\begin{array}{l}\text { Degree of } \\
\text { freedom }\end{array}$ & Mean square & $F$ value & $P$ value \\
\hline Inlet flow & $9.346 \mathrm{E}-05$ & 4 & $2.336 \mathrm{E}-05$ & 0.609 & $6.645 \mathrm{E}-01$ \\
Sediment content & 0.013 & 4 & 0.003 & 87.810 & $2.850 \mathrm{E}-08^{* * *}$ \\
Water separator type & 0.002 & 3 & 0.001 & 20.352 & $8.530 \mathrm{E}-05^{* * *}$ \\
Filter area & 0.008 & 2 & 0.004 & 105.722 & $6.576 \mathrm{E}-08^{* * *}$ \\
Error & 0.000 & 11 & $3.835 \mathrm{E}-05$ & & \\
Total & 0.024 & 24 & & & \\
\hline
\end{tabular}

$* * * P<0.001, * * P<0.01, * P<0.05$

\section{Analysis of variance of total filtration efficiency}

The results of the analysis of variance of the total filtration efficiency are shown in Table 6. The filter area had the most significant impact on the total filtration efficiency under turbid water conditions. This means that the filter area was the most critical factor affecting the total filtration efficiency of the filter, followed by the sediment content, then the water separator type, and finally, the inlet flow (insignificant effect).

The clogging rate of a mesh filter is not high during initial filtration. However, with the increase in the sediment carrying capacity of the water flow, the sediment particles with sizes equal to the mesh size are easily embedded in the mesh, which will accelerate the mesh blockage. Thus, a mesh filter can easily form a filter cake. The larger the mesh area is, the larger the formed cake becomes. At this time, the sediment is affected by water flow disturbances, which weakens the adsorption and bridging effect of solid particles in muddy water on the mesh, resulting in a large amount of sediment deposition in the mesh. The greater the sediment concentration is, the greater the trapped sediment mass in the mesh filter becomes. Therefore, the main factors affecting the total filtration efficiency and the trapped sediment mass are the filter area and the sediment concentration. The influences of the main factors on the total filtration efficiency and the trapped sediment mass were analysed using the filtering mechanism, and the reliability of the ranking of the factors obtained from the ANOVA was further examined.

\section{Multiple comparison analysis of main effects}

Table 7 shows the multiple ratio results of the main effects. The sediment content had a significant impact on the trapped sediment mass. When $S$ was set at different levels, the difference in the trapped sediment mass was significant. When the water separator type was set at different levels, the difference in the trapped sediment mass between the different treatments was not significant. However, the trapped sediment mass at levels $C_{2}, C_{3}$, and $C_{4}$ is greater than that at level $C_{1}$. For different filter areas, the difference in the trapped sediment mass was not significant. Nevertheless, a larger filter area corresponded to a higher trapped sediment mass.

The sediment content had a significant impact on the total filtration efficiency. The results for $S_{5}$ were significantly different from those for $S_{1}$ and $S_{2}$. The results for $S_{3}$ and $S_{4}$ were significantly different from those for $S_{1}$, and the results for the other levels were not significantly different. The type of water separator had a significant effect on the total filtration efficiency, but the difference between the different treatments was not significant. The results for the filter screen area $A_{1}$ were significantly different from the results for $A_{2}$ and $A_{3}$. An increased filter area improved total the filtration efficiency. Although the type of water separator had a significant effect on the trapped sediment mass and total filtration efficiency, the difference between the groups was not significant. Therefore, the water separator type was not considered when establishing the prediction models of the trapped sediment mass and the total filtration efficiency. 
Table 7 Multiple comparison results of the main effects
Table 8 Factors affecting the trapped sediment mass of the filter

\begin{tabular}{|c|c|c|c|c|c|c|}
\hline \multirow[t]{2}{*}{ Factor } & \multicolumn{3}{|c|}{ Trapped sediment mass } & \multicolumn{3}{|c|}{ Total filtration efficiency } \\
\hline & Level & Average value & $\begin{array}{l}\text { Significance } \\
\text { level } \alpha=0.05\end{array}$ & Level & Average value & $\begin{array}{l}\text { Signifi- } \\
\text { cance level } \\
\alpha=0.05\end{array}$ \\
\hline \multirow[t]{5}{*}{ Inlet flow Q } & 5 & 301.52 & - & 5 & 0.8833 & - \\
\hline & 3 & 308.04 & - & 4 & 0.8839 & - \\
\hline & 1 & 308.10 & - & 3 & 0.8866 & - \\
\hline & 2 & 309.08 & - & 1 & 0.8870 & - \\
\hline & 4 & 310.77 & - & 2 & 0.8884 & - \\
\hline \multirow[t]{5}{*}{ Sediment content $S$} & 1 & 105.90 & $\mathrm{a}$ & 5 & 0.8616 & $\mathrm{a}$ \\
\hline & 2 & 206.68 & $\mathrm{~b}$ & 4 & 0.8671 & $a b$ \\
\hline & 3 & 309.06 & $\mathrm{c}$ & 3 & 0.8778 & $\mathrm{ab}$ \\
\hline & 4 & 412.31 & $\mathrm{~d}$ & 2 & 0.8974 & $\mathrm{bc}$ \\
\hline & 5 & 503.56 & $\mathrm{e}$ & 1 & 0.9253 & $\mathrm{c}$ \\
\hline \multirow[t]{4}{*}{ Water separator type C } & 1 & 299.95 & $\mathrm{a}$ & 1 & 0.8746 & $\mathrm{a}$ \\
\hline & 3 & 309.54 & $\mathrm{a}$ & 3 & 0.8889 & a \\
\hline & 2 & 310.24 & $\mathrm{a}$ & 2 & 0.8930 & $\mathrm{a}$ \\
\hline & 4 & 317.83 & $\mathrm{a}$ & 4 & 0.8982 & $\mathrm{a}$ \\
\hline \multirow[t]{3}{*}{ Filter area A } & 1 & 300.62 & $\mathrm{a}$ & 1 & 0.8647 & $\mathrm{a}$ \\
\hline & 2 & 311.84 & $\mathrm{a}$ & 2 & 0.8954 & $\mathrm{~b}$ \\
\hline & 3 & 312.60 & $\mathrm{a}$ & 3 & 0.9091 & $\mathrm{~b}$ \\
\hline
\end{tabular}

\begin{tabular}{lllll}
\hline Variable type & Name & Symbol & Unit & Dimension \\
\hline Dependent variable & Trapped sediment mass & $R_{m}$ & $\mathrm{~kg}$ & {$[\mathrm{M}]$} \\
Independent variable & Diameter of connecting pipe & $D$ & $\mathrm{~m}$ & {$[\mathrm{~L}]$} \\
& Inlet flow & $Q$ & $\mathrm{~m} / \mathrm{s}$ & {$\left[\mathrm{L}^{3} \mathrm{~T}^{-1}\right]$} \\
& Water density & $\rho$ & $\mathrm{kg} / \mathrm{m}^{3}$ & {$\left[\mathrm{ML}^{-3}\right]$} \\
& Flow rate of connecting pipe & $v$ & $\mathrm{~m} / \mathrm{s}$ & {$\left[\mathrm{LT}^{-1}\right]$} \\
& Average flow rate of filter screen & $v_{f}$ & $\mathrm{~m} / \mathrm{s}$ & {$\left[\mathrm{LT}^{-1}\right]$} \\
& Dynamic viscosity & $\mu$ & $\mathrm{Pa} \cdot \mathrm{s}$ & {$\left[\mathrm{ML}^{-1} \mathrm{~T}^{-1}\right]$} \\
& Filter length & $L_{l}$ & $\mathrm{~m}$ & {$\left[\mathrm{~L}^{-1}\right.$} \\
& Gravitational acceleration & $g$ & $\mathrm{~m} / \mathrm{s}^{2}$ & {$\left[\mathrm{LT}^{-2}\right]$} \\
& Filter area & $A$ & $\mathrm{~m}$ & {$\left[\mathrm{~L}^{2}\right]$} \\
& Filter aperture & $d_{k}$ & $\mathrm{~m}$ & {$[\mathrm{~L}]$} \\
& Sediment content & $S$ & $\mathrm{~kg} / \mathrm{m}^{3}$ & {$\left[\mathrm{ML}^{-3}\right]$} \\
\hline
\end{tabular}

\section{Establishment of prediction model of trapped sediment mass}

Table 8 shows the factors that affected the mass of trapped sediment by the filter screen. To investigate the relationship between the filter screen's trapped sediment mass $R_{m}$ and the connecting pipe diameter $D$, inlet flow $Q$, and water density $\rho$, the experimental data were first processed to calculate the values of the relevant dimensionless items. The SPSS 25.0 software was then used to perform multiple regression analysis to obtain the relevant parameters. Finally, the prediction model of the trapped sediment mass of the filter screen could be obtained.
The relationship between the filter's trapped sediment mass and each physical quantity under turbid water conditions can be expressed as follows:

$f\left(R_{m}, D, Q, \rho, v, v_{f}, \mu, L_{1}, g, A, d_{k}, S\right)=0$.

According to the $\pi$ theorem of dimensional analysis, the aperture $d_{k}$ of the filter screen, flow velocity of the connecting pipe $v$, and water density $\rho$ were taken as the basic physical quantities, and $\pi_{i}$ was used to represent the dimensionless quantities. The following dimensionless groups were obtained: 


$$
\begin{aligned}
& \pi_{1}=\frac{R_{m}}{d_{k}^{3} \rho}, \\
& \pi_{2}=\frac{Q}{d_{k}^{2} v}, \\
& \pi_{3}=\frac{v_{f}}{v}, \\
& \pi_{4}=\frac{\mu}{\rho v d_{k}}, \\
& \pi_{5}=\frac{L_{1}}{d_{k}}, \\
& \pi_{8}=\frac{D}{d_{k}}, \\
& \pi_{6}=\frac{d_{k} g}{v^{2}}, \\
& \pi_{7}=\frac{A}{d_{k}^{2}}, \\
& \pi_{9}
\end{aligned}
$$

Therefore, the relationship between the trapped sediment mass of the filter screen and influencing parameters was expressed as follows: analysis. The normal $\mathrm{P}-\mathrm{P}$ diagram of the regression standardized residual is shown in Fig. 3.

The empirical coefficients, indices, and regression analysis results of Eq. (12) are shown in Table 9. The $R^{2}$ was as high as 0.998 , indicating that the measured data were highly consistent with the simulated data. In addition, the root mean square error was only 0.0263 , indicating that the prediction error was small. Some $\pi$ terms had an exponent of 0 . This was because for a filter with a specific structure, the dimensionless $\pi$ terms obtained from certain geometric variables were constant or uncorrelated, and thus, they were removed from the model. In the multiple regression analysis process, $P$ was set to 0.05 .

Table 10 shows the results of the analysis of variance for the prediction model of trapped sediment mass for the turbid water filter. For the prediction model $P$ was less than 0.001 , indicating that the model was significant.

After substituting the parameters of the regression model obtained through multiple regression analysis into Eq. (12), the following equation for the filter screen's trapped sediment mass under turbid water conditions was obtained:

$\frac{R_{m}}{d_{k}^{3} \rho}=e^{23.724}\left(\frac{A}{d_{k}^{2}}\right)^{0.061}\left(\frac{S}{\rho}\right)^{0.976}$

Thus, the mass of trapped sediment of the filter screen under turbid water conditions was mainly related to the sediment content, water density, filter area, and filter aperture. The combined effect of these parameters determined the total mass of trapped sediment of the filter screen under different working conditions.

Figure 4 compares the predicted values [following

$\frac{R_{m}}{d_{k}^{3} \rho}=\lambda_{1}\left(\frac{Q}{d_{k}^{2} v}\right)^{n_{1}}\left(\frac{v_{f}}{v}\right)^{n_{2}}\left(\frac{\mu}{\rho v d_{k}}\right)^{n_{3}}\left(\frac{L_{1}}{d_{k}}\right)^{n_{4}}\left(\frac{d_{k} g}{v^{2}}\right)^{n_{5}}\left(\frac{A}{d_{k}^{2}}\right)^{n_{6}}\left(\frac{D}{d_{k}}\right)^{n_{7}}\left(\frac{S}{\rho}\right)^{n_{8}}$,

where $\lambda_{1}$ is an empirical coefficient, and $n_{1}, n_{2}, n_{3}, n_{4}, n_{5}, n_{6}$, $n_{7}$, and $n_{8}$ are empirical indices. The coefficient and indices were determined through experiments.

After sorting the test data related to the trapped sediment mass and recording it in a spreadsheet, these dimensionless groups were logarithmically transformed. Multiple regression analysis was performed using the SPSS 25.0 software. The stepwise regression method was adopted for the regression. Similarly, the normality and homogeneity of the variance of the data were tested before the multiple regression analysis. When the assumptions were met, it indicated that multiple regression analysis could be performed. The testing indicated that the data met the assumptions and could be subjected to multiple regression
Eq. (13)] of the trapped sediment mass with the measured values. The average relative error of the predicted mass of trapped sediment was $2.05 \%$. The measured and predicted values of trapped sediment mass were very close, indicating that the model could accurately predict the trapped sediment mass of the filter screen under turbid water conditions. The feasibility of using these parameters to predict the trapped sediment mass under different experimental conditions was verified. The prediction model has a certain degree of error, and hence, it can generate overly high or low values under certain conditions.

To verify the accuracy of the prediction model for the sediment mass trapped by the filter, five sets of experimental data selected in advance were used to verify the prediction results of the model. The experimental data when different 
Fig. 3 Normal P-P plot of standardized regression residuals

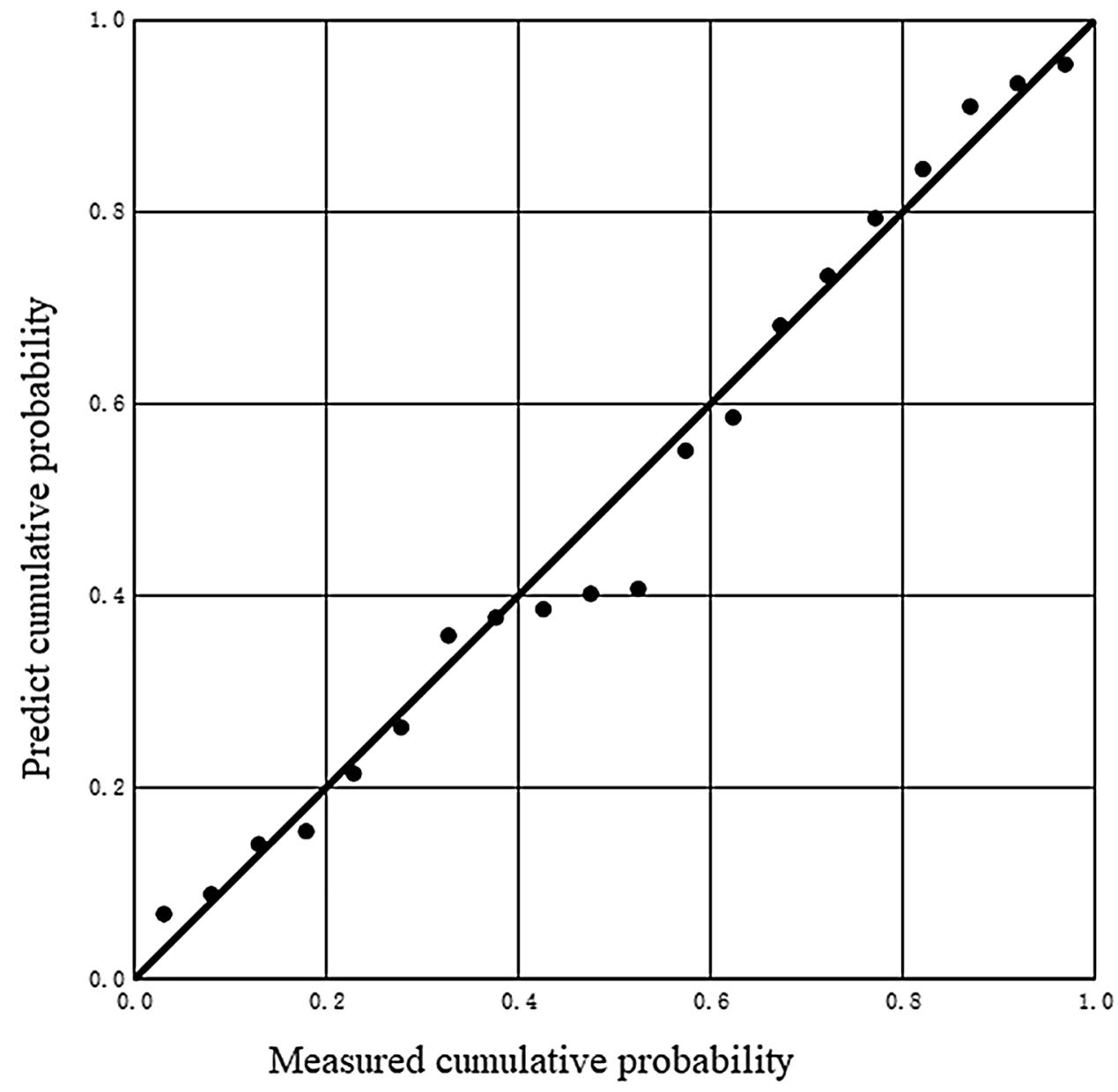

Table 9 Regression analysis results of the trapped sediment mass of the filter

Table 10 Analysis of variance results of the prediction model of the trapped sediment mass of the filter

\begin{tabular}{|c|c|c|c|c|c|c|c|}
\hline Equation & Coefficients & $\mathrm{d}$ in & ces & $\begin{array}{l}\text { Standardized } \\
\text { coefficients }\end{array}$ & Significance & $\begin{array}{l}\text { Coefficient of } \\
\text { determination }\end{array}$ & $\begin{array}{l}\text { Root mean } \\
\text { square } \\
\text { error }\end{array}$ \\
\hline \multirow[t]{9}{*}{ (12) } & Coefficients & $\lambda_{1}$ & $e^{23.724}$ & & $6.480 \mathrm{E}-21 * * *$ & 0.998 & 0.0263 \\
\hline & Indices & $n_{1}$ & 0 & & & & \\
\hline & & $n_{2}$ & 0 & & & & \\
\hline & & $n_{3}$ & 0 & & & & \\
\hline & & $n_{4}$ & 0 & & & & \\
\hline & & $n_{5}$ & 0 & & & & \\
\hline & & $n_{6}$ & 0.061 & 0.026 & $3.107 \mathrm{E}-02 *$ & & \\
\hline & & $n_{7}$ & 0 & & & & \\
\hline & & $n_{8}$ & 0.976 & 0.999 & $2.781 \mathrm{E}-24 * * *$ & & \\
\hline
\end{tabular}

$* * * P<0.001, * * P<0.01, * P<0.05$

\begin{tabular}{llclll}
\hline Model & Sum of squares & $\begin{array}{l}\text { Degree of } \\
\text { freedom }\end{array}$ & Mean square & $F$ value & $P$ value \\
\hline Regression & 5.702 & 2 & 2.851 & 4123.541 & $1.454 \mathrm{E}-23^{* * *}$ \\
Residual error & 0.012 & 17 & 0.001 & & \\
Total & 5.713 & 19 & & & \\
\hline
\end{tabular}

$* * * P<0.001, * * P<0.01, * P<0.05$ 


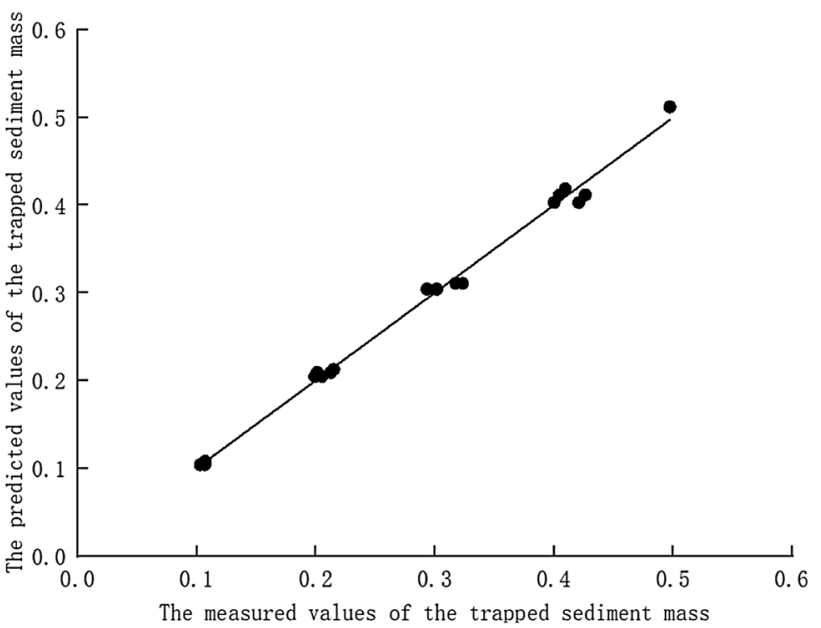

Fig. 4 Comparison of measured and predicted values of trapped sediment mass

filter elements were added under different experimental conditions were substituted into Eq. (13), and the predicted values of the trapped sediment mass of the filter under different experimental conditions were calculated and compared with the measured values, as shown in Table 11. The maximum relative error between the predicted and measured values of the trapped sediment mass was $5.31 \%$, and the minimum relative error was only $0.16 \%$. These results indicate that the model could estimate the mass of trapped sediment with high accuracy.

\section{Establishment of prediction model of total filtration efficiency}

The method and steps for establishing the prediction model of the total filtration efficiency were the same as those of the trapped sediment mass. The relationship between the total filtration efficiency $\eta$ (dependent variable) of the filter and the independent variables in Table 8 can be expressed as follows:

$f\left(\eta, A, S, Q, \rho, \nu, \nu_{f}, \mu, L_{1}, g, D, d_{k}\right)=0$.

Based on the same basic physical quantities used in the establishment of the prediction model of trapped sediment mass, the dimensionless groups can be expressed by Eqs. (4)-(11) and the following equation:

$\pi_{10}=\eta$.

Therefore, the relationship between the total filtration efficiency of the filter and the influencing factors can be expressed as follows:
Table 11 Validation of the prediction model of the trapped sediment mass of the filter

\begin{tabular}{lllllll}
\hline $\begin{array}{l}\text { Working con- } \\
\text { dition }\end{array}$ & $\ln \left(\frac{R_{m}}{d_{k}^{2} \rho}\right)$ & $\ln \left(\frac{A}{d_{k}^{2}}\right)$ & $\ln \left(\frac{S}{\rho}\right)$ & $\begin{array}{l}\text { Measured value } \\
(\mathrm{m})\end{array}$ & $\begin{array}{l}\text { Predicted value } \\
(\mathrm{m})\end{array}$ & $\begin{array}{l}\text { Relative } \\
\text { error }(\%)\end{array}$ \\
\hline 1 & 18.34 & 16.03 & -6.50 & 0.3096 & 0.3162 & 2.13 \\
2 & 18.77 & 15.41 & -5.99 & 0.4759 & 0.5012 & 5.31 \\
3 & 18.82 & 15.41 & -5.99 & 0.5001 & 0.5012 & 0.22 \\
4 & 18.86 & 15.77 & -5.99 & 0.523 & 0.5123 & 2.05 \\
5 & 18.86 & 16.03 & -5.99 & 0.5214 & 0.5206 & 0.16 \\
\hline
\end{tabular}

Table 12 Regression analysis results of the total filtration efficiency

\begin{tabular}{|c|c|c|c|c|c|c|c|}
\hline \multirow[t]{2}{*}{ Equation } & \multicolumn{3}{|c|}{ Coefficients and indices } & \multirow{2}{*}{$\begin{array}{l}\text { Standardized } \\
\text { coefficient }\end{array}$} & $P$ & $\begin{array}{l}\text { Coefficient of } \\
\text { determination }\end{array}$ & $\begin{array}{l}\text { Root mean } \\
\text { square } \\
\text { error }\end{array}$ \\
\hline & Coefficients & $\lambda_{2}$ & $e^{-0.767}$ & & $2.528 \mathrm{E}-10$ & 0.889 & 0.0125 \\
\hline & Indices & $k_{l}$ & 0 & & & & \\
\hline & & $k_{2}$ & -0.086 & -0.562 & $2.382 \mathrm{E}-06$ & & \\
\hline & & $k_{3}$ & 0 & & & & \\
\hline & & $k_{4}$ & 0 & & & & \\
\hline & & $k_{5}$ & 0 & & & & \\
\hline & & $k_{6}$ & 0 & & & & \\
\hline & & $k_{7}$ & 0 & & & & \\
\hline & & $k_{8}$ & -0.047 & -0.751 & $4.652 \mathrm{E}-08$ & & \\
\hline
\end{tabular}


Table 13 Analysis of variance results of the prediction model of the total filtration efficiency

\begin{tabular}{llclll}
\hline Model & Sum of squares & $\begin{array}{l}\text { Degree of } \\
\text { freedom }\end{array}$ & Mean square & $F$ value & $P$ value \\
\hline Regression & 0.021 & 2 & 0.011 & 67.773 & $7.942 \mathrm{E}-9$ \\
Residual error & 0.003 & 17 & 0.000 & & \\
Total & 0.024 & 19 & & & \\
\hline
\end{tabular}

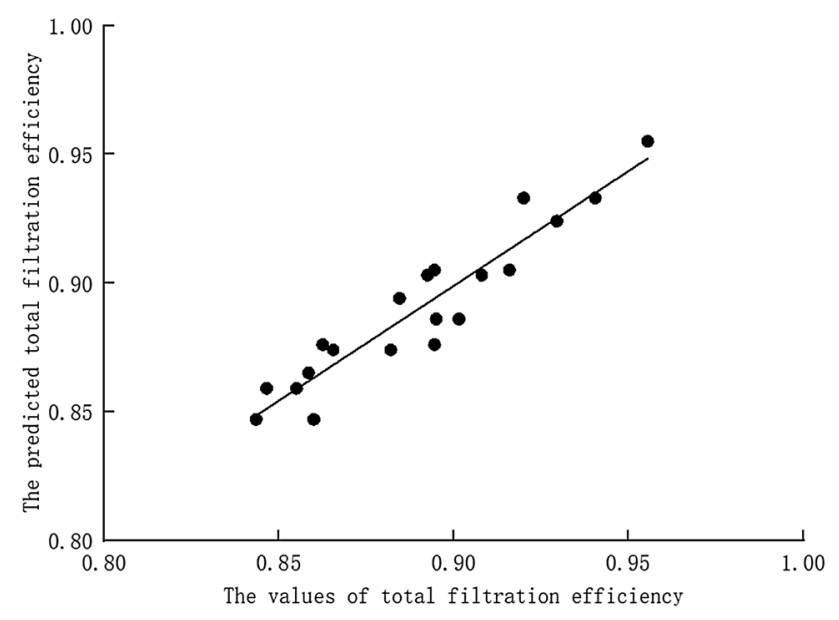

Fig. 5 Comparison of measured and predicted values of total filtration efficiency
After substituting the model parameters obtained from the multiple regression analysis into Eq. (16), the following prediction equation of the total filtration efficiency for the filter under turbid water conditions was obtained:

$\eta=e^{-0.767}\left(\frac{v_{f}}{v}\right)^{-0.086}\left(\frac{S}{\rho}\right)^{-0.047}$.

Thus, the total filtration efficiency of the filter screen under turbid water conditions is mainly related to the sediment content, water density, flow rate of the connecting pipe, and average flow rate of the filter screen. Since the diameter of the connecting pipe was fixed during the experiment, the flow rate of the connecting pipe and the filter screen depended on the inlet flow and filter area. The combined effect of these parameters determined the total filtration efficiency of the filter under different working conditions.

The values of total filtration efficiency calculated by

$\eta=\lambda_{2}\left(\frac{Q}{d_{k}^{2} v}\right)^{n_{1}}\left(\frac{v_{f}}{v}\right)^{n_{2}}\left(\frac{\mu}{\rho v d_{k}}\right)^{n_{3}}\left(\frac{L_{1}}{d_{k}}\right)^{n_{4}}\left(\frac{d_{k} g}{v^{2}}\right)^{n_{5}}\left(\frac{A}{d_{k}^{2}}\right)^{n_{6}}\left(\frac{D}{d_{k}}\right)^{n_{7}}\left(\frac{S}{\rho}\right)^{n_{8}}$,

where $\lambda_{2}$ is an empirical coefficient, and $k_{1}, k_{2}, k_{3}, k_{4}, k_{5}, k_{6}$, $k_{7}$, and $k_{8}$ are empirical indices. The coefficient and indices will be determined through experiments.

The empirical coefficients, indices, and regression analysis results of Eq. (16) are shown in Table 12. The $R^{2}$ was 0.889 , which indicated the high correlation between the measured and simulated values. The root mean square error was 0.0125 , and the prediction error was small.

Table 13 presents the results of the analysis of variance of the total filtration efficiency prediction model. The prediction model $\mathrm{p}$ was less than 0.001 . Hence, the model was significant.
Eq. (17) were compared with the measured values, as shown in Fig. 5. The predicted total filtration efficiency was close to the measured value, indicating the ability of the model to accurately predict the total filtration efficiency of the filter under turbid water conditions. It also reveals the feasibility of using these parameters to predict the total filtration efficiency under different experimental conditions. The prediction model contained a certain degree of error, so in some cases, the predicted value could be overly high or low.

To verify the accuracy of the prediction model of the total filter efficiency of the filter, five sets of experimental data selected in advance were used to verify the predicted results.
Table 14 Verification of the prediction model of the total filtration efficiency of filter

\begin{tabular}{lllllll}
\hline $\begin{array}{l}\text { Working con- } \\
\text { dition }\end{array}$ & $\ln (\eta)$ & $\ln \left(\frac{v_{f}}{v}\right)$ & $\ln \left(\frac{S}{\rho}\right)$ & $\begin{array}{l}\text { Measured value } \\
(\mathrm{m})\end{array}$ & $\begin{array}{l}\text { Predicted value } \\
(\mathrm{m})\end{array}$ & $\begin{array}{l}\text { Relative } \\
\text { error }(\%)\end{array}$ \\
\hline 1 & -0.12 & -4.19 & -6.50 & 0.891 & 0.904 & 1.44 \\
2 & -0.19 & -3.57 & -5.99 & 0.830 & 0.836 & 0.77 \\
3 & -0.17 & -3.57 & -5.99 & 0.844 & 0.836 & 0.90 \\
4 & -0.12 & -3.93 & -5.99 & 0.891 & 0.863 & 3.13 \\
5 & -0.12 & -4.19 & -5.99 & 0.885 & 0.882 & 0.29 \\
\hline
\end{tabular}


The experimental data with different filter elements added under different experimental conditions were substituted into Eq. (17) to predict the corresponding values of the total filtration efficiency. A comparison between the predicted and measured values is shown in Table 14. The table shows that the maximum relative error between the predicted and measured values was $3.13 \%$, and the minimum relative error was $0.29 \%$. The model accuracy was high, and thus, it could better predict the total filtration efficiency.

Many researchers have established head loss prediction models of post-pump filters, mainly through physical experiments combined with dimensional analysis and other methods, and achieved good prediction results (Mesquita et al. 2012; Elbana et al. 2013; Puig-Bargues et al. 2005; Duran-Ros et al. 2010; Yurdem et al. 2008; Zong et al. 2015; Elbana et al. 2012). On the basis of physical test data, a prediction model of the trapped sediment mass and the total filtration efficiency of a pre-pump micro-pressure filter was established using dimensional analysis and multiple regression analysis. The maximum relative error of the prediction model was only $5.31 \%$, and the accuracy was high. Therefore, this model can be used to predict the trapped sediment mass and total filtration efficiency of the pre-pump micropressure filter. The multiple regression analysis method used in this paper is a hypothetical modelling method, that is, the original data must satisfy normality and variance homogeneity requirements. The physical test data in this article satisfied these assumptions, and thus, they can be directly used to calculate the trapped sediment mass and total filtration efficiency. However, data often do not satisfy normality, and it is necessary to transform the data to meet this requirement. Due to the heavy workload, an assumption-free modelling method can be used in a future study, such as projection pursuit regression. This method does not assume a distribution type of the test data, it avoids unreasonable constraints of human factors on the regression model, and it overcomes the confirmatory data analysis methods (Zheng et al. 1998; Jiang et al. 2019). The experiments in the paper were carried out under conditions with sediment contents of $0.5-2.5 \mathrm{~g} / \mathrm{L}$, inlet flows of $2-8 \mathrm{~m}^{3} / \mathrm{h}$, filter areas of $1105-2060 \mathrm{~cm}^{2}$, and four water separator types. If the conditions deviate from the levels of these four factors, further verification is needed.

\section{Conclusions}

Based on an indoor physical model experiment of a prepump micro-pressure filter, the influences of the inlet flow, sediment content, water separator type, and filter area on the trapped sediment mass and total filtration efficiency were investigated.
1. Through analysis of variance, the influence of various factors on the mass of trapped sediment was in the following descending order: sediment content, filter area, water separator type, and inlet flow. The impact of each factor on the total filtration efficiency was in the following descending order: filter area, sediment content, water separator type, and inlet flow. Multiple comparisons of the significant factors in the analysis of variance showed that the water separator type could significantly affect the mass of trapped sediment and the total filtration efficiency. Nevertheless, the difference between the water separator types was not significant.

2. By combining dimensional analysis with multiple linear regression, prediction models of the trapped sediment mass and the total filtration efficiency under turbid water conditions were developed. The expressions are $\frac{R_{m}}{d^{3} \rho}=e^{23.724}\left(\frac{A}{d^{2}}\right)^{0.061}\left(\frac{S}{\rho}\right)^{0.976} \quad$ a $n \quad d$ $\eta=e^{-0.767}\left(\frac{v_{f}}{v}\right)^{-0.086}\left(\frac{S}{\rho}\right)^{-0.047}$. The coefficient of determination $R^{2}$ of the model exceeded 0.889 . The established model was verified. The relative error of the prediction was small, and the model was able generate accurate predictions.

The constructed prediction models are suitable when the sediment content, inlet flow, filter area, and sediment particle size distribution range are known. For other conditions, further study is needed. The above research results provide a further reference for the filtration performances of pre-pump micro-pressure filters.

Acknowledgements This study was financially supported by Tianshan Youth Plan, a Xinjiang Uygur Autonomous Region Innovation Environment (Talent, Base) Construction special project (2019Q075), and a group-supporting project of studying abroad funded by the Xinjiang Uygur Autonomous Region People's Government in 2019.

\section{Declarations}

Conflict of interest The authors declare that they have no conflicts of interest.

Open Access This article is licensed under a Creative Commons Attribution 4.0 International License, which permits use, sharing, adaptation, distribution and reproduction in any medium or format, as long as you give appropriate credit to the original author(s) and the source, provide a link to the Creative Commons licence, and indicate if changes were made. The images or other third party material in this article are included in the article's Creative Commons licence, unless indicated otherwise in a credit line to the material. If material is not included in the article's Creative Commons licence and your intended use is not permitted by statutory regulation or exceeds the permitted use, you will need to obtain permission directly from the copyright holder. To view a copy of this licence, visit http://creativecommons.org/licenses/by/4.0/. 


\section{References}

Adin A (1987) Clogging in irrigation systems reusing pond effluents and its prevention. Water Sci Technol 19:323-328

Bové J, Arbat G, Duran-Ros M et al (2015) Pressure drop across sand and recycled glass media used in micro irrigation filters. Biosys Eng 137:55-63

Capra A, Scicolone B (2007) Emitter and filter tests for wastewater reuse by drip irrigation. Agric Water Manag 68(2):135-149

Dai JH, Yuan J (2016) Comparison of single-factor analysis of variance and multiple linear regression analysis. Stat Decis 9(453):23-26 (in Chinese with English abstract)

De Souza FH, Roecker PB, Silveira DD et al (2021) Influence of slow sand filter cleaning process type on filter media biomass: backwashing versus scraping. Water Res 189:1-12

Demir V, Yurdem H, Yazgi A et al (2009) Determination of the head losses in metal body disc filters used in drip irrigation systems. Turk J Agric for 33(3):219-229

Deus FPD, Mesquita M, Ramirez JCS et al (2020) Hydraulic characterisation of the backwash process in sand filters used in micro irrigation. Biosyst Eng 192:188-198

Duran-Ros M, Arbat G, Barragán J et al (2010) Assessment of head loss equations developed with dimensional analysis for microirrigation filters using effluents. Biosyst Eng 106:521-526

Elbana M, Ramírez de Cartagena F, Puig-bargués J (2012) Effectiveness of sand media filters for removing turbidity and recovering dissolved oxygen from a reclaimed effluent used for micro-irrigation. Agric Water Manag 111:27-33

Elbana M, Ramírez de Cartagena F, Puig-Bargués J (2013) New mathematical model for computing head loss across sand media filter for microirrigation systems. Irrig Sci 31(03):343-349

Garcia Nieto PJ, Garcia Gonzalo E, Arbat G et al (2018) Pressure drop modelling in sand filters in micro-irrigation using gradient boosted regression trees. Biosys Eng 171:41-51

García-Nieto PJ, García-Gonzalo E, Puig-Bargués J et al (2020) Prediction of outlet dissolved oxygen in micro-irrigation sand media filters using a Gaussian process regression. Biosys Eng 195:198-207

Jiang CM, Gong JW, Tang XJ et al (2019) Optimization method of comprehensive of low heat cement cementitious system based Projection Pursuit Regression. J Build Mater 22(03):333-340

Jiao YQ, Feng J, Liu YZ et al (2020) Sustainable operation mode of a sand filter in a drip irrigation system using Yellow River water in an arid area. Water Supply 20(8):3545-3636

Li JH, Zhai GL, Huang XQ et al (2016a) Numerical simulation and flow field analysis of backwashing of quartz sand filter in microirrigation. Trans Chin Soc Agric Eng 32(9):74-82 (in Chinese with English abstract)

Li YK, Feng J, Song P et al (2016b) Developing situation and system construction of low-carbon environment friendly drip irrigation technology. Trans Chin Soc Agric Mach 47(06):83-92 (in Chinese with English abstract)

Li JH, Cai JM, Zhai GL et al (2018) Optimization of backwashing speed based on transient simulation of water volume fraction in sand filter layer. Trans Chin Soc Agric Eng 34(2):83-89 (in Chinese with English abstract)

Liu ZJ, Shi K, Xi Y et al (2021) Hydraulic performance of self-priming mesh filter for micro-irrigation in northwest China. Agric Res. https://doi.org/10.1007/S40003-020-00531-X (prepublish)

Mesquita M, Testezlaf R, Ramirez JCS (2012) The effect of media bed characteristics and internal auxiliary elements on sand filter head loss. Agric Water Manag 115:178-185
Mesquita M, Deus FPD, Testezlaf R et al (2019) Design and hydrodynamic performance testing of a new pressure sand filter diffuser plate using numerical simulation. Biosyst Eng 183:58-69

Price JF (2003) Dimensional analysis of models and data sets. Am J Phys 71(5):437-447

Puig-Bargues J, Barragain J, Ramires F et al (2005) Development of equations for calculating the head loss in effluent filtration in microirrigation systems using dimensional analysis. Biosyst Eng 92(03):383-390

Pujol T, Puig-Bargués J, Arbat G et al (2020a) Effect of wand-type underdrains on the hydraulic performance of pressurised sand media filters. Biosyst Eng 192:176-187

Pujol T, Puig Bargués J, Arbat G et al (2020b) Numerical study of the effects of pod, wand and spike type underdrain systems in pressurised sand filters. Biosyst Eng 200:338-352

Solé-Torres C, Puig-Bargués J, Duran-Ros M et al (2019a) Effect of underdrain design, media height and filtration velocity on the performance of microirrigation sand filters using reclaimed effluents. Biosyst Eng 187:292-304

Solé-Torres C, Puig-Bargués J, Duran-Ros M et al (2019b) Effect of different sand filter underdrain designs on emitter clogging using reclaimed effluents. Agric Water Manag 223:1-9

Tao HF, Zhou Y, Li Q et al (2020a) Micro pressure filter in front of pump: China, 202020260675.0[P]. 2020a-11-03

Tao HF, Zhou Y, Yang WX et al (2020b) Filtration efficiency of selfcleaning drum-shaped mesh continuous filter. Desalin Water Treat 208:227-238

Wu WY, Chen W, Liu HL et al (2014) A new model for head loss assessment of screen filters developed with dimensional analysis in drip irrigation systems. Irrig Drain 63:523-531

Yang PL, Lu P, Ren SM et al (2019a) Comprehensive evaluation method for hydraulic performance and filtering quality of laminated filter. Trans Chin Soc Agric Eng 35(19):134-141 (in Chinese with English abstract)

Yang PL, Lu P, Ren SM et al (2019b) Experiment on performance of disc filter based on fractal theory. Trans Chin Soc Agric Mach 50(02):218-226 (in Chinese with English abstract)

Yurdem H, Demir V, Degirmencioglu A (2008) Development of a mathematical model to predict head losses from disc filters in drip irrigation systems using dimensional analysis. Biosyst Eng 100:14-23

Zhang WZ, Cai JM, Lv MC et al (2020) Experimental study on influencing factors of filtration effect of sand filter. J Irrig Drain 39(07):77-83 (in Chinese with English abstract)

Zheng ZG, Yang LX (1998) Projection pursuit long-range forecast and verification for three gorges annual maximum flood-peak flow in 1998. J Xinjiang Agric Univ 1998(04):60-63 (in Chinese with English abstract)

Zhou LQ, Han D, Yu LM et al (2020) Effects of guide vanes on performance of Y-screen filter. Trans Chin Soc Agric Eng 36(12):40-46 (in Chinese with English abstract)

Zong QL, Zheng TG, Liu HF et al (2015) Development of head loss equations for self-cleaning screen filters in drip irrigation systems using dimensional analysis. Biosyst Eng 133:116-127

Zong QL, Liu ZJ, Liu HF et al (2019) Backwashing performance of self-cleaning screen filters in drip irrigation systems. PLoS ONE 14(12):1-18

Publisher's Note Springer Nature remains neutral with regard to jurisdictional claims in published maps and institutional affiliations. 